\title{
Study of foot length measurement as a screening tool to identify low birth weight and preterm neonates
}

\author{
Mehta R. ${ }^{1}$, Dhaneria M. ${ }^{2}$, Prajapati J. ${ }^{3 *}$ \\ DOI: https://doi.org/10.17511/ijpr.2020.i07.04
}

\footnotetext{
${ }^{1}$ Rishika Mehta, Senior Resident, Department of Paediatrics, RD Gardi Medical College, Ujjain, Madhya Pradesh, India.

2 Mamta Dhaneria, Professor and Head, Department of Paediatrics, RD Gardi Medical College, Ujjain, Madhya Pradesh, India.

3* Jyoti Prajapati, Assistant Professor, Department of Pediatrics, MGM Medical College and MY Hospital, Indore, Madhya Pradesh, India.
}

Introduction: Low birth weight is an important indicator of survival, future growth, and overall development of the child. It is associated with socio-economic, clinical, racial, hereditary, personal, and geographical factors. Method: This prospective observational study was conducted during the 19 months in the nursery and postnatal wards at RDGMC, Ujjain. All live birth newborns were assessed within 24 hours of birth. All Sick babies requiring NICU care, newborns with congenital malformation were excluded from the study. For each newborn recruited in the study length of the left foot was measured from the heel to the tip of the big toe using a hard transparent plastic ruler which was pressed vertically against the babies' sole and the reading was recorded. The data was analyzed in Epidata (version 3.1) and then transferred to Stata10.0 (Stata Corp College Station, Texas, U.S.A) for statistical analysis. Results: (1) Foot length measurement was directly correlated with gestational age with cut off being $6.3 \mathrm{~cm}$ for 32 weeks, $6.6 \mathrm{~cm}$ for 36 weeks, and $7.35 \mathrm{~cm}$ for > 36 weeks. (2) Foot length measurement directly correlated with the birth weight with the cut off for VLBW babies being $6.25 \mathrm{~cm}$, for weight< $2000 \mathrm{gm}$ being $6.78 \mathrm{~cm}$ and LBW being $7.92 \mathrm{~cm}$. Conclusion: Present study strongly recommends foot length measurement as an easy, fast, accurate, and low-cost tool for predicting prematurity and low birth weight not only in the hospital setup but also for community health providers.

Keywords: Preterm, foot length, screening tool, Low birth weight, preterm

\section{Corresponding Author}

Jyoti Prajapati, Assistant Professor, Department of Pediatrics, MGM Medical College and MY Hospital, Indore, Madhya Pradesh, India.

Email: drjyotimdpedia108@gmail.com

\section{How to Cite this Article}

Mehta R, Dhaneria M, Prajapati J. Study of foot length measurement as a screening tool to identify low birth weight and preterm neonates. Pediatric Rev Int J Pediatr Res. 2020;7(7):337-343.

Available From

https://pediatrics.medresearch.in/index.php/ijpr/arti cle/view/622
To Browse

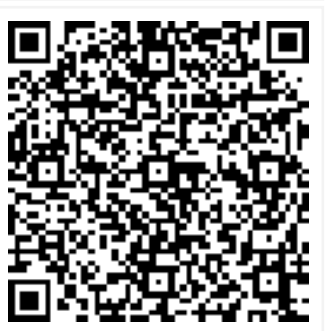

Manuscript Received 2020-08-30

Conflict of Interest No
Review Round 1 2020-08-29

Funding $\mathrm{Nil}$

$\begin{gathered}\text { Review Round } 2 \\ 2020-09-15\end{gathered}$
Ethical Approval
Yes

Review Round 3

Accepted 2020-10-18

Plagiarism $\mathbf{X}$-checker $4 \%$

Note

(c) 2020 by Rishika Mehta, Mamta Dhaneria, Jyoti Prajapati and Published by Siddharth Health Research and Social Welfare Society. This is an Open Access article licensed under a Creative Commons Attribution 4.0 International License https://creativecommons.org/licenses/by/4.0/ unported [CC BY 4.0]. 


\section{Introduction}

In India, a large proportion of newborn deaths, contributing to an estimated $52 \%$ of all infant deaths, occur in the first week of life. Major causes of neonatal mortality are diseases associated with preterm birth, low birth weight (LBW), and lethal congenital anomalies. Later on, low birth weight is also associated with post-neonatal mortality and with infant and childhood morbidity. Low birth weight accounts for about two-thirds of all perinatal and $57 \%$ of all infant deaths in India $[1,2]$.

Thus birth weight is an important indicator of survival, future growth, and overall development of the child. It is associated with socio-economic, clinical, racial, hereditary, personal, and geographical factors[3]. This underlines the importance of early identification of low birth weight and preterm babies. But the situation is made worse in rural and distant set up with poor resources as lack of trained or expert health care staff and lack of basic facilities[2,4]. In India, the physical growth of a newborn is evaluated by comparing body measurements such as weight, length, and $\mathrm{HC}$, with standards established in Western countries [5].

To determine gestational age in newborns, clinicians in developed countries rely on various prenatal and postnatal indicators such as first-trimester ultrasound, last menstrual period [6], and neonatal Scales such as Dubowitz or Ballard scoring systems [7]. The date of the last menstrual period is not very reliable because many mothers have irregular cycles and many cannot recall the exact date. USG is out of reach in rural and distant set up due to lack of resources and lack of trained staff $[3,4]$.

This emphasizes for need an alternative measurement that can reliably predict low birth weight and prematurity. These alternative measurements should be easy, reliable, having a very good correlation with both birth weight and gestational age, and should have a very little intra and inter-observer variability. Assessment of the gestational age by Ballard's scoring is timeconsuming and requires expertise and cannot be used in the community as it requires training of the workers in using New Ballard's score. Moreover, it is time-consuming which can cause delayed referrals to higher centers. The tool used for measuring such a parameter for determining LBW and prematurity should be simple so that even an untrained health care staff can do the measurement reliably.
Foot length is one such parameter that can be used easily in preterm and sick neonates without disturbing the baby. Foot length is easy to measure and does not require much expertise [8]. It will be worthwhile to determine if foot length correlates with gestational age assessment by New Ballard scoring. This study is undertaken to study a simple method like foot length to assess the gestational age of a newborn and also tries to validate by comparing it with New Ballard's score.

\section{Method}

Study design and Setting: This prospective observational study was conducted during the 19 months in postnatal wards of RDGMC, Ujjain.

Inclusion criteria: All the live birth newborns were assessed within 24 hours of birth, who were available for examination.

Exclusion Criteria: All Sick newborns requiring intensive NICU care and born with congenital malformation were excluded from the study.

Sample Collection and method: For each newborn recruited in the study length of the left foot was measured from the heel to the tip of the big toe using a hard transparent plastic ruler which was pressed vertically against the babies' sole and the reading was recorded.

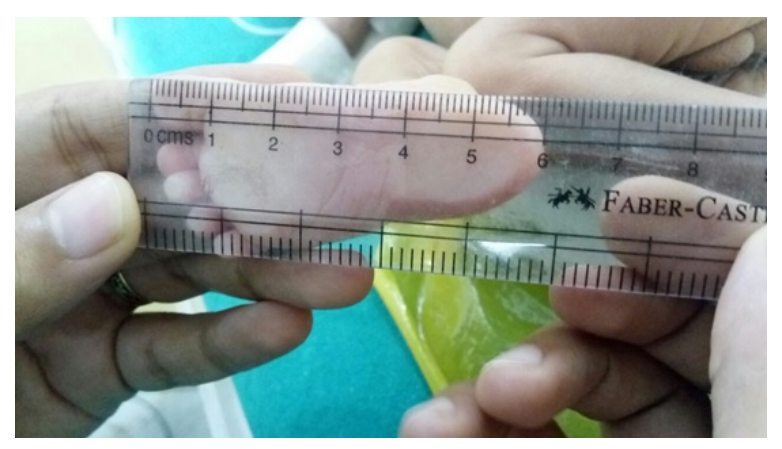

Fig-1: Hard transparent plastic ruler which was pressed vertically against the babies' sole.

Other anthropometric measurements as weight, $\mathrm{HC}$, CC, length, and sociodemographic data were recorded on a preformed written questionnaire after taking informed consent. GA was assessed using New Ballard's score. To ensure inter-observer variation, one data collector was trained to carry out all anthropometric measurements in newborns.

Statistical analysis: The data was entered in Epidata (version 3.1) and then transferred to Stata 10.0 (Stata Corp College Station, Texas, U.S.A). 
Continuous variables were reported as mean and standard deviation while categorical variables were given as the number or the percentage of newborns with the characteristic of interest. Pearson's product-moment correlation coefficient was used to assess the association between anthropometric measurements like head circumference, chest circumference, birth weight, and total length with foot length.

Receiver operating characteristic (ROC) curves were used to evaluate the accuracy of different anthropometric measurements and specifically for foot length to predict two outcomes; Low birth weight and Prematurity. Low birth weight was coded as dichotomous ( $1=$ yes; $0=$ no). The area under the ROC curve (AUC) was calculated using the nonparametric method of De Long.

Sensitivity, specificity, likelihood ratio for a positive test and likelihood ratio for a negative test was calculated. p-value $<0.05$ was considered statistically significant. All statistical tests were twotailed.

\section{Results}

A total of 497 neonates (51\% males and $49 \%$ females)were enrolled for the study. $64 \%$ belonged to the rural population. Out of $497,44 \%$ were preterm and $56 \%$ were term, $96 \%$ were inborn, and $75 \%$ were delivered by normal vaginal delivery.
Linear correlation of Ballard's score and foot length with birth weight, head circumference, chest circumference, and Total length (crown heel length) was found statistically significant (Table 1 ).

Table-1: Distribution of study group according to the various anthropometric indices including foot length.

\begin{tabular}{|l|l|l|l|l|l|}
\hline \multirow{2}{*}{} & \multicolumn{2}{|c|}{ Males $(\mathrm{n}=\mathbf{2 5 4})$} & \multicolumn{2}{c|}{ Females $(\mathrm{n}=243)$} & P- \\
\cline { 2 - 5 } & Mean (S.D.) & $95 \%$ C.I. & Mean (S.D.) & $95 \%$ C.I. & value \\
\hline Birth weight & $\begin{array}{l}2052.594 \\
(620.083)\end{array}$ & $1976-$ & $\begin{array}{l}1917.181 \\
(570.3801)\end{array}$ & $1845-$ & 0.01 \\
\hline $\begin{array}{l}\text { Head } \\
\text { circumference }\end{array}$ & $\begin{array}{l}29.34252 \\
(2.93486)\end{array}$ & $29-30$ & $\begin{array}{l}28.66667 \\
(2.420641)\end{array}$ & $28-29$ & 0.005 \\
\hline $\begin{array}{l}\text { Chest } \\
\text { circumference }\end{array}$ & $\begin{array}{l}26.37402 \\
(2.69054)\end{array}$ & $26-27$ & $\begin{array}{l}25.74897 \\
(2.500981)\end{array}$ & $25-26$ & 0.007 \\
\hline Total length & $\begin{array}{l}42.77165 \\
(5.72224)\end{array}$ & $42-43$ & $\begin{array}{l}41.52263 \\
(5.05859)\end{array}$ & $41-42$ & 0.01 \\
\hline Foot length & 7.051575 & $7.0-7.1$ & $\begin{array}{l}6.90823 \\
(0.58671)\end{array}$ & $6.8-7.0$ & 0.01 \\
\hline
\end{tabular}

Mean birth weight, length, head circumference, chest circumference, and foot length were higher in male babies than female, and the difference is statistically significant

It was observed that birth weight is directly correlated with Ballard's score and Ballard's score increases as birth weight increases $(r=0.6663)$; $\mathrm{P}<0.001$. [table2] Similarly there is a direct correlation between Ballard's score and foot length $(r=0.6669)$ so as the gestational age increased foot length increased proportionately. $\mathrm{P}<0.001$ (Table-2).

Table-2: Correlation between New Ballard Score and various anthropometric measurements.

\begin{tabular}{|l|l|l|l|l|l|}
\hline & \multicolumn{1}{|c|}{ Birth weight $(\mathrm{cm})$} & \multicolumn{1}{|c|}{ Head circumference $(\mathrm{cm})$} & \multicolumn{1}{|c|}{ Chest circumference $(\mathrm{cm})$} & Total length & Foot length \\
\hline Ballard score & 0.6663 & 0.6167 & 0.1763 & $0.9237^{*}$ & 0.6669 \\
\hline Birth weight & 1.000 & 0.8623 & 0.2349 & $0.9293^{*}$ & $0.9786 *$ \\
\hline Head circumference & & 1.000 & 0.2336 & 0.8554 & 0.8662 \\
\hline Chest circumference & & & 1.0000 & 0.2161 & 0.2425 \\
\hline Total length & & & & 1.0000 & $0.9237 *$ \\
\hline
\end{tabular}

A Pearson's product-moment correlation between the New Ballard scoring method and anthropometric data shows a direct correlation between the Ballard score and Birth weight, head circumference, total length, and foot length of the baby. $(p=<0.005)$
There is a direct correlation between birth weight, head circumference, total length, and foot length of the baby. There was a strong correlation between the foot length and weight of the child ( $r=0.9786)$; $\mathrm{P}<0.001$, with foot length explaining $95.76 \%$ of the variation in weight of the child (Table 2 ). 
Table-3: Correlation of foot length with gestational age and birth weight.

\begin{tabular}{|l|l|l|l|l|l|l|l|}
\hline $\begin{array}{c}\text { Outcome } \\
\text { variable }\end{array}$ & $\begin{array}{c}\text { ROC- } \\
\text { AUC }\end{array}$ & $\begin{array}{c}\text { Standard } \\
\text { Error }\end{array}$ & $\begin{array}{c}\text { Sensitivity } \\
(\%)\end{array}$ & $\begin{array}{c}\text { Specificity } \\
(\%)\end{array}$ & $\begin{array}{c}\text { Positive Predictive } \\
\text { Value(\%) }\end{array}$ & $\begin{array}{c}\text { Negative Predictive } \\
\text { Value(\%) }\end{array}$ & $\begin{array}{c}\text { Correctly Classified } \\
(\%)\end{array}$ \\
\hline GA & $0.9092 *$ & 0.0081 & 85.91 & 77.98 & 75.60 & 87.45 & 81.49 \\
\hline Birth weight & $0.9979 *$ & $(1.01) 7$ & 98.73 & 91.35 & 97.73 & 90.91 & 97.18 \\
\hline
\end{tabular}

Foot length has relatively low sensitivity, specificity, the likelihood ratio for the positive test and negative predictive value for GA, and has a high sensitivity, specificity, likelihood for positive as well as negative predictive value for birth weight.

There was a strong correlation between the foot length and gestational age; $\mathrm{P}<0.001$, with foot length explaining $44.7 \%$ of the variation in gestational age. As far as birth weight is concerned foot length has a high sensitivity (98.73\%), specificity $(91.35 \%)$, the likelihood for positive $(97.73 \%)$ as well as a negative test $(90.91 \%)$ (Table 3$)$. Foot length has a relatively low sensitivity $(85.9 \%)$, specificity $(77.98 \%)$, the likelihood ratio for a positive test (75.60\%), and negative predictive value(87.24\%) for GA. Only $81.49 \%$ values were determined as correctly classified but had a statistically significant correlation on the ROC curve. (Figure 2).

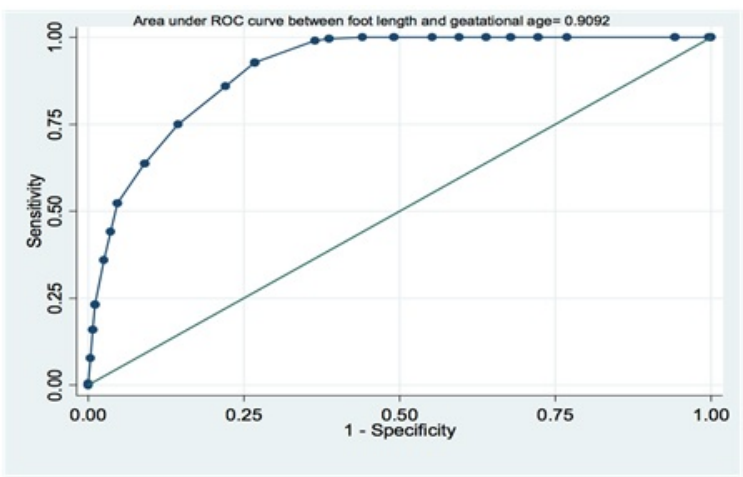

Fig-1: The ROC curve for foot length to predict gestational age with the area under curve being 0.9092 which is statistically significant.

\section{Discussion}

This study was done to find out the correlation between foot length, gestational age, and birth weight in neonates, so that foot length can be used as a proxy measurement for estimation of gestational age and birth weight. In the present study group, 393 babies (79\%) were low birth weight out of which 121 newborns (65\%) were very low birth weight (VLBW) while 198 newborns (40\%) had birth weight between 1501-2000 grams,
74 neonates (15\%) were between 2001-2500 grams. 104 neonates weighed $>2.5 \mathrm{~kg}$ with a mean weight of $1984 \mathrm{gm}$. In this study, none of the newborns below $1000 \mathrm{gm}$ were included. In this study, the majority of newborns were termed $56 \%$, while $44 \%$ were preterm with a mean gestational age of 35.7 weeks. The preterm percentage is higher in the present study in comparison to other studies $[8,9,10,11,12]$, giving us more precise values for prematurity and low birth weight babies.

The foot length of neonates in the present study ranged from $5.9-8.2 \mathrm{~cm}$ with a mean foot length of $7.0515 \mathrm{~cm}$ and $6.9082 \mathrm{~cm}$ for males and female neonates respectively [Table 1]. And mean foot length of neonates increased as the gestational age increased. $(p=0.020)$. (Table 4). This closely correlates with other studies $[13,10,14,15]$.

Table-4: Mean foot lengths of the study group according to age categories.

\begin{tabular}{|l|l|l|}
\hline \multicolumn{1}{|c|}{$\begin{array}{l}\text { Age Categories (in weeks) } \\
\mathbf{n = 4 9 7}\end{array}$} & \multicolumn{1}{|c|}{$\begin{array}{c}\text { Foot length (in } \\
\mathbf{c m})\end{array}$} & \multicolumn{1}{|c|}{$\begin{array}{c}\text { Standard } \\
\text { deviation }\end{array}$} \\
\hline $28-32$ (Group A) & $6.33(\mathrm{n}=81)$ & 0.33 \\
\hline $33-37$ (Group B) & $6.61(\mathrm{n}=140)$ & 0.255 \\
\hline 37 (Group C) & $7.35(\mathrm{n}=276)$ & 0.53 \\
\hline
\end{tabular}

Mean foot length increases as the gestational age increases. $(p=0.02)$

However, a study by James D.K. et al [12] means foot length was higher than that observed in the present study being 7.92 for term neonates against ours because the present study included both preterm and term newborns. A similar result was obtained with a higher mean foot length of 7.72 $(0.02)$ and $7.838 \mathrm{~cm}$ in a study $[11,16]$ for term neonates. Also, mean foot length correlated directly with the birth weight of neonates (Table 5).

Table-5: Mean foot length according to birth weight.

\begin{tabular}{|l|l|}
\hline \multicolumn{1}{|c|}{$\begin{array}{c}\text { Birth weight Categories (in grams) } \\
\mathrm{n}=497\end{array}$} & Mean foot length (in cm) \\
\hline $1000-1500$ & $6.254(\mathrm{n}=121)$ \\
\hline $1501-2000$ & $6.78(\mathrm{n}=198)$ \\
\hline $2001-2500$ & $7.34(\mathrm{n}=74)$ \\
\hline$>2500$ & $7.92(\mathrm{n}=104)$ \\
\hline
\end{tabular}


Mean foot length increases as birth weight increases $(p=0.02)$.

This observation is closely related to the study by James D.K. et al [12] where mean foot length was found to be $7.92 \mathrm{~cm}$ in infants with birth weight > $2500 \mathrm{gms}$. In the present study the Area Under the Curve for birth weight of infants with foot length was highly significant i.e.0.9979 (Figure 3).

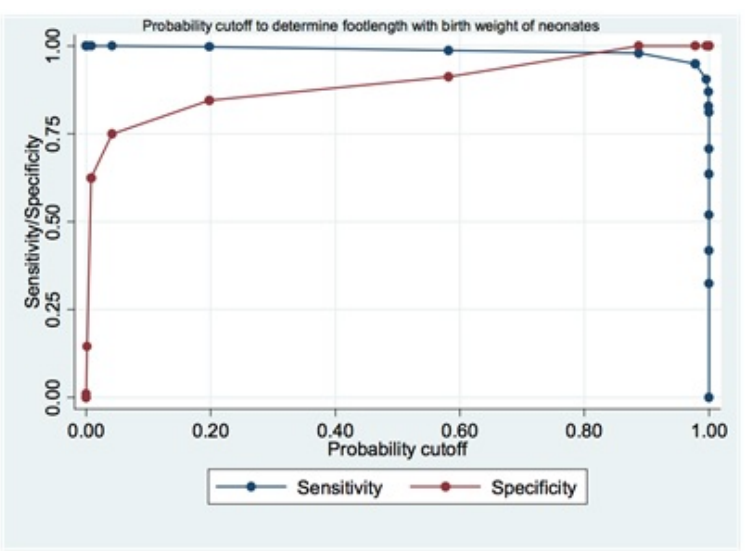

Fig-3: Probability cut off for foot length with birth weight on $x$-axis plotted against sensitivity and specificity on the y-axis. The probability cut off being 0.85 which is highly significant.

Table-6: Pearson Correlation of foot length with birth weight and gestational age in various studies (r-value).

\begin{tabular}{|l|l|l|}
\hline \multicolumn{1}{|c|}{ Studies } & \multicolumn{1}{|c|}{$\begin{array}{c}\text { Foot length to birth } \\
\text { weight correlation }(\mathbf{r})\end{array}$} & $\begin{array}{c}\text { Foot length to gestational } \\
\text { age correlation( } \mathbf{r})\end{array}$ \\
\hline $\begin{array}{l}\text { Present } \\
\text { study }\end{array}$ & 0.9786 & 0.6669 \\
\hline $\begin{array}{l}\text { S.R. Daga et } \\
\text { al.[13] }\end{array}$ & 0.9000 & 0.868 \\
\hline $\begin{array}{l}\text { Gohil et al } \\
\text { [10] }\end{array}$ & 0.973 & 0.869 \\
\hline $\begin{array}{l}\text { Srivastava } \\
\text { et al [15] }\end{array}$ & 0.97 & 0.99 \\
\hline $\begin{array}{l}\text { Mathur et al } \\
{[14]}\end{array}$ & 0.89 & 0.91 \\
\hline
\end{tabular}

The ROC-AUC decreased to 0.9092 when gestational age alone was plotted against foot length [Figure 2]. Similar results were observed by Tashkande et al [16] where ROC-AUC was obtained for various anthropometric measurements and the best discrimination of LBW as detected by ROC-area under the curve was obtained by foot length with AUC of 0.909. AUC by Mullany LC et al [17] for foot length for identification of LBW infants was 0.88 .
In the study by Ashish KC et al [11] for foot length comparison with low birth weight (<2000grams) were comparable with AUC being $87.8 \%$, but showed a wide variation when foot length was plotted with gestational age with AUC being 68.3\%. Also, AUC obtained by Saroj et al [9] for foot length to be compared with low birth weight was found to be 0.724 , which is not comparable to the results of the present study.

The present study also studied other anthropometric data for neonatal assessment and observed that head circumference of male newborns was higher than female [Table1] and gestational age increased as head circumference increased, $(p<0.005)$. The mean head circumference for preterm neonates was $26.965 \mathrm{~cm}$ and the term was $30.36 \mathrm{~cm}$. This data was compared with the study by Gohil JR et al [10] which showed mean head circumference for preterm neonates $29.1 \pm 1.64 \mathrm{~cm}$.

In the present study, the correlation was better in low birth weight neonates as compared to the preterm neonates, and foot length correlated significantly with gestational age, birth weight, head circumference, and Total length.[Table1]. Other studies $[10,12]$ also showed similar results. The present study observed a direct correlation between the Ballard score to Birth weight, head circumference, total length, and foot length of the neonates. And there was a strong co-relation between foot length and weight of the child $(r=0.9786) ; P<0.001$, with foot length explaining $95.76 \%$ of the variation in weight of child [Table 2].

According to observation by the present study low birth weight can be identified if foot length is $<7.34$ $\mathrm{cm} .(p=0.02)$. Similarly, foot length is directly correlated with the gestational age, prematurity can be identified if foot length $<6.61 \mathrm{~cm} .(p=0.02)$.

\section{Conclusion}

The present study observed that a foot length is a sensitive tool in determining accurate gestational age and birth weight of the newborn. And can be a good tool especially in rural and distant settings where detailed examination of a newborn using Ballard's score is not possible where it can be used by community health providers for identification of gestational age in low birth weight newborns as well as in normal-weight newborns. A foot length can also be used for assessment of prematurity in sick and mechanically ventilated newborns where the Ballard score cannot be applied. 
In a developing country like India, the standard charts can be made according to weight, gestational age, and corresponding foot length and can be used by health workers in the community for early identification and early referral of preterm and low birth weight neonates to referral centers. Early identification and timely referral of these newborns will help in reducing neonatal mortality and morbidity.

\section{What does the study add to the existing knowledge}

Foot length measurement is an easy, fast, accurate, and low-cost tool for predicting prematurity and low birth weight not only in the hands of health personal in the hospital setup but also for community health providers.

\section{Author's contribution}

Dr. Rishika Mehta: Concept, data collection, study design

Dr. Mamta Dhaneria: Study design, Statistical analysis

Dr. Jyoti Prajapati: Manuscript preparation

\section{Reference}

01. Park K. Park's Textbook of Preventive and Social Medicine. 24th ed, Jabalpur- M/S Banarsidas Bhanot. Page no-605.

[Crossref]

02. Paul VK, Sachdev HS, Mavalankar D, et al. Reproductive health, and child health and nutrition in India- meeting the chal-lenge. Lancet. 2011;377(9762)332-349.

doi:10.1016/S0140-6736(10)61492-4 [Crossref]

03. Howson C P, Kinney MV, McDougall L, Lawn JE. Born Too Soon Preterm Birth Action Group, Born too soon- preterm birth matters. Reproduct Health. $2013 ; 10(1) S 1$.

doi: 10.1186/1742-4755-10-S1-S1 [Crossref]

04. Bang AT, Bang RA, Baitule S, Deshmukh $M$, Reddy $\mathrm{MH}$. Burden of morbidities and the unmet need for health care in rural neonates- a prospective observational study in Gadchiroli, India. Indian Pediatr. 2001;38(9)952-965.

[Crossref]
05. Sharma JN, Saxena S, Sharma U. Relationship between birth weight and other neonatal anthropometeric parameters. Indian Pediatr. $1988 ; 25(3) 244-248$.

[Crossref]

06. P Opara. Gestational Age Assessment In The Newborn - A Review. Internet J Pediatr Neonatol. 2009;12;2.

[Crossref]

07. Ballard JL, Khoury JC, Wedig K, Wang L, EilersWalsman BL, Lipp R. New Ballard Score, expanded to include extremely premature infants. J Pediatr. 1991;119(3)417-423.

doi: $10.1016 / s 0022-3476(05) 82056-6$ [Crossref]

08. Mukherjee $S$, Roy $P$, Mitra $S$, Samanta $M$, Chatterjee $S$. Measuring new-born foot length to identify small babies in need of extra care- a cross-sectional hospital based study. Iran J Pediatr. 2013;23(5)508-512.

[Crossref]

09. Saroj DA, Sharma D, Singh, DM. Measurement of Neonatal Foot Length to Identify Low Birth Weight Babies- a cross-sectional hospital-based study. J Dent Med Sci. 2016;15(6).

[Crossref]

10. Gohil JR, Sosi M, Vani SN, Desai AB. Foot length measurement in the neonate. Indian $\mathrm{J}$ Pediatr. $1991 ; 58(5) 675-677$.

doi: $10.1007 /$ BF02820189 [Crossref]

11. KC A, Nelin V, Vitrakoti R, Aryal S, Målqvist $M$. Validation of the foot length measure as an alternative tool to identify low birth weight and preterm babies in a low-resource setting like Nepal- a cross-sectional study. BMC Pediatr. $2015 ; 15 ; 43$.

doi: $10.1186 / \mathrm{s} 12887-015-0361-4 \quad$ [Crossref]

12. James DK, Dryburgh EH, Chiswick ML. Foot length-a new and potentially useful measurement in the neonate. Arch Dis Child. 1979;54(3)226-230.

doi: $10.1136 /$ adc.54.3.226 [Crossref]

13. Daga SR, Daga AS, Patole S, Kadam S, Mukadam Y. Foot Length Measurement from Foot Print for Identifying a Newborn at Risk. J Trop Pediatr. 1988;34(1)16-19.

doi: $10.1093 /$ tropej/34.1.16 [Crossref] 
14. Mathur A, Tak SK, Kothari P. 'Foot length'-a newer approach in neonatal anthropometry. J Trop Pediatr. $1984 ; 30(6) 333-336$.

doi: $10.1093 /$ tropej/30.6.333 [Crossref]

15. Anshuman S Sharma, Utkarsh S, Sumit K. To study correlation of foot length and gestational age of new born by new Ballard score. Int J Res Med Sci. 2017;3(11)3119-3122.

doi: $10.18203 / 2320-6012 . i j r m s 20151147$ [Crossref]
16. Amar MT, Rewat M, Amol L. Neonatal Foot Length- An Alternative Predictor of Low Birth Weight Babies in Rural India. Acad J Ped Neonatol. 2016;1(4)555-569.

doi: 10.19080/AJPN.2016.01.555569 [Crossref]

17. Mullany LC, Darmstadt GL, Khatry SK, Leclerq SC, Tielsch JM. Relationship between the surrogate anthropometric measures, foot length and chest circumference and birth weight among newborns of Sarlahi, Nepal. Eur J Clin Nutr. 2007;61(1)40-46.

doi:10.1038/sj.ejcn.1602504 [Crossref] 